\title{
Key Technologies and Applications of 10GW-Level Wind and Solar Power Plant Cluster Controlling
}

\author{
ZHOU Qiang ${ }^{1,2, a}$,WANG Ning-bo ${ }^{1,2}$, HE Shi-en ${ }^{1,2}$, MA Yan-hong ${ }^{2,3}, \mathrm{CHEN}$ \\ Zhao $^{1,2}$ and WANG Ming-song ${ }^{1,2}$ \\ ${ }^{1}$ Wind Power Technology Center of Gansu Electric Power Company , China \\ ${ }^{2}$ Wind Power Engineering and Technology Research Center of Gansu, China \\ ${ }^{3}$ State Grid Gansu Electric Power Company, China \\ aeezhouqiang@163.com
}

\begin{abstract}
Keywords: Scenery cluster, resource monitoring network, combined power forecasting, active / reactive power / smooth integration control, cluster control demonstration project

Abstract. According to China's new energy large-scale centralized development which brings some problems, such as: resource monitoring, electric power forecast, cluster modeling, active / reactive power / security and stability of the coordinated control and demonstration project construction, design and development of the large-scale wind farm photovoltaic power station cluster control system, which has successfully operated in Gansu Hexi new energy base. Built the wind metering network and the operation of network which covered in Gansu Hexi new energy base, completed the unit - station cluster modeling, developed the intelligent active / reactive power / safe and stable triple control device, including the design of operation dispatching center station, coordinated control of master station, sub station and perform four level control cluster system architecture, the demonstration projects has achieved good results.
\end{abstract}

\section{Introduction}

Since the 1970s to 1980 s, the global occurred two serious oil crisis, in the background of fossil energy supply difficulties and the global ecological deteriorating environment, in order to optimize the structure of energy resources and foster strategic emerging industries, States around the world have introduced incentive policies to promote the development of new energy sources, new energy has become the main content of the new energy revolution. As an important driver "engine" of the world economy, the demand for energy resources is increasing day by day. In order to achieve safe, efficient, clean, sustainable development, China has proposed the new energy strategy with a wealth of natural resources, formulated the "Renewable Energy Law" and other policies to support the new energy high-speed, large-scale and high-level development.

\section{New Energy Development Status}

The primary task of the new round of energy revolution is based on the security of energy supply to achieve a low-carbon energy development ${ }^{[1]}$. Wind power and photovoltaic power due to its own advantage is becoming the world most promising large-scale development of renewable energy, countries around the world has regarded it as the inevitable trend of the future energy development ${ }^{[7-8]}$.

\section{Development of Wind Power}

Since 2006, the development of wind power in China has went into the fast lane ${ }^{[2-6]}$, By the end of 2017 ,the global cumulative wind power installed capacity reached $539581 \mathrm{MW}$, this number of China is $195021 \mathrm{MW}$, the cumulative and new installed capacity in China ranks first in the world. 2004-2017 China cumulative installed wind capacity and share of global proportion curve shown in Fig. 1, 2004-2017 China cumulative installed photovoltaic capacity and share of global proportion curve shown in Fig. 2. 


\section{Development of Photovoltaic power}

Since 2010,following the rapid development of wind power, the photovoltaic power of China has went into a high-speed growth cycle. By the end of 2017, the cumulative global photovoltaic capacity has reached 390100MW, and the number of China is 130120MW, 2004-2017 China cumulative installed photovoltaic capacity and share of global proportion curve shown as Fig. 2.
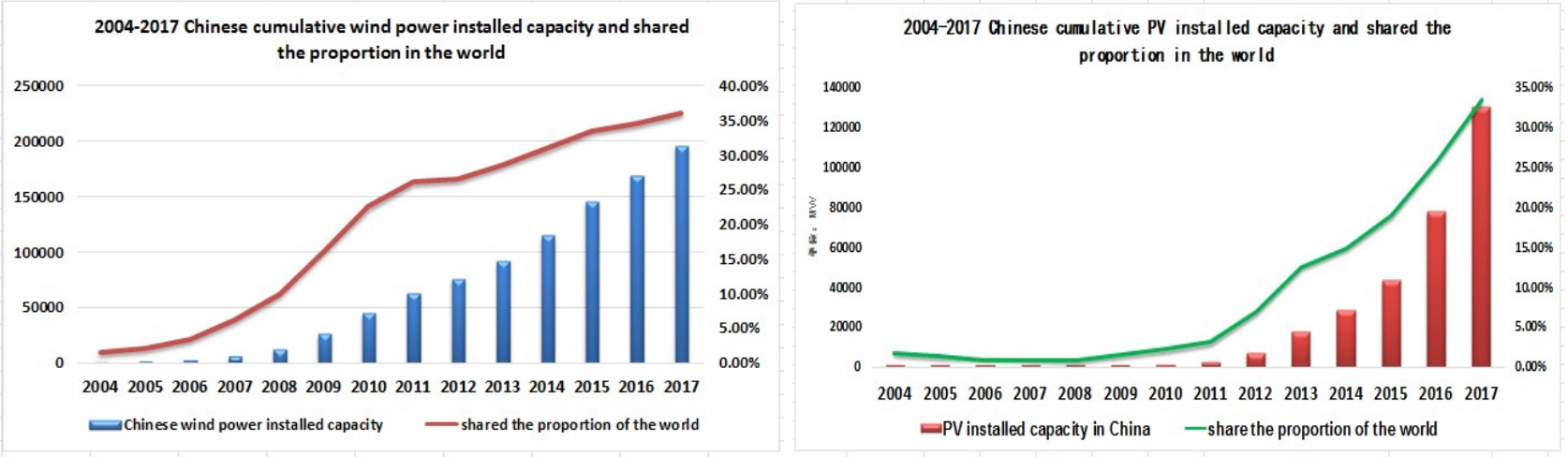

Fig. 1 2004-2017 China installed wind capacity Fig. 2 2004-2017 China installed PV capacity and share of global proportion and share of global proportion

Wind power and photovoltaic power development of China bring enormous economic and social benefits in recent year, due to the distribution of wind and light resources reverse with electrical load, which makes the "large-scale cluster development, sending long-distance" has become the main mode of China's new energy development. Less controllable batch of new energy sources, and its multi-temporal volatility and anti-peaking characteristics, resulting in difficulty adjusting frequency and peak value, system stability is threatened, power output is limited, its economy is difficult to guarantee, "great power, weak grid" grid mode impacts on the security and stability operation, which present a huge challenge for the existing power grid control technologies and operational mode, these factors has become a major bottleneck which affect the health and sustainable development of China's new energy.How to stabilize the wind and photovoltaic power randomness and volatility, which makes large-scale wind and photovoltaic clusters can be measured, adjustable, controllable; How to implement large-scale wind power and photovoltaic power fair, accurate, fast and reliable control, making wind and photovoltaic power has the characteristics of conventional energy sources, reducing abandoned wind, abandoned photovoltaic capacity has become a worldwide problem.

\section{Wind and phovoltaic cluster control system functions}

Hexi Corridor of Gansu province has abundant wind and solar energy resources, which has the good conditions for the construction of large-scale new energy base, by the of 2017, Gansu wind power capacity reaches to $12821 \mathrm{WM}$, accounting for $26.47 \%$ of the province's installed capacity, ranking second in China, and seventh in the world. Photovoltaic power installed capacity reach to $6870 \mathrm{WM}$, accounting for the province's installed capacity of $14.18 \%$, rank first in the country, is also ranked seventh worldwide. The problem in Gansu renewed energy base has typical and representative, Based on this background, State Grid Power Company in Gansu Province led to undertake 863 project "wind farms, photovoltaic power plants cluster control system research and development", which explores a whole new energy control method to administrate and integrate the large-scale wind farms and photovltaic power plants, making the efficient interaction between the power dispatch center and new energy efficient interactive unit.

\section{Research contents and ideas}

The subject mainly research wind turbine and photovoltaic modules, the output characteristics of photovoltaic power plants, wind power plants and clusters, the priority is to breakthrough the cluster control policy and control system development, constructing the demonstration project of wind farms 
and photovoltaic power plants cluster control system, which can be connected with the existing power generation output forecasting, power dispatching system, information communication system and so . The research ideas shown in Fig.3.

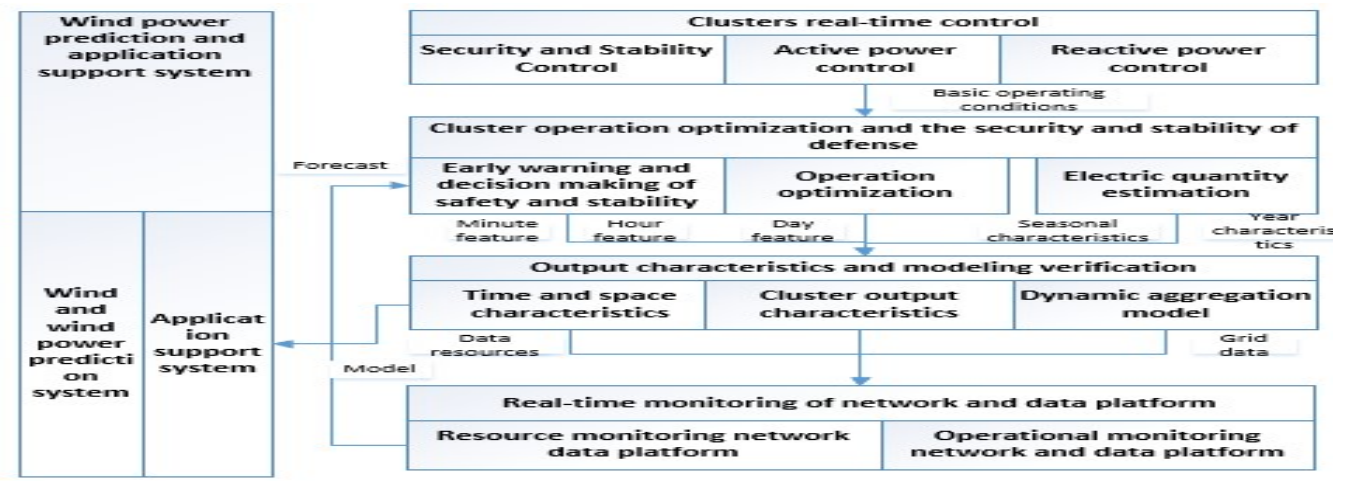

\section{Key technology}

Fig. 3 Scenery cluster control system technology roadmap

1)Built the world's largest high-density real-time wind power, photovoltaic power monitoring network and resource monitoring network, containing 44 anemometer towers, 18 metering stations, the resources and run real-time monitoring information of 67 wind farms with 4412 wind turbines and 103 photovoltaic power plants with 21900000 photovoltaic components is connected by the system, which solves the observability of large-scale new energy clusters. The monitoring network achieves the five world records, access capacity of photovoltaic, the number of wind turbine and photovoltaic modules, light irradiation observation density, resources near ground observation means, the data accumulated by the data center.

2) Implement a new energy forecasting system run in parallel, proposed the comprehensive system of wind and photovoltaic forecasting, which realized the lateral correlation and comprehensive evaluation of multiple data sources, multiple sets of lateral prediction accuracy. The system covers the whole area of Gansu over 95\% of the grid-connected photovoltaic power station and wind farm, Combined power short-term prediction (0-24 hours) monthly root mean square error is less than $20 \%$ and ultra short-term forecast error is less than $15 \%$, the prediction accuracy meet the practical needs of production scheduling department.

3)Developed main control devices which contain coordinated cluster system, control sub-station, perform station, which has already used in hundreds of Gansu Hexi substation. Developed cluster control devices which has active, reactive, security and stability control trinity, which effectively improve the cluster control performance.

4) Innovation of the "machine - field - Station - Network" multi-level coordination cluster reactive power and voltage mode and strategy, which multidimensional progressively stabilize the voltage fluctuations from time scale, spatial distribution and control objectives. Reactive power and voltage control mode as shown in Fig.4.

5) Based on the "hierarchical partition" concept, design the four level control system which constitutes by a dispatch center station, 5 control master station, 40 control sub-stations and 75 action station has features of clear hierarchy, clear function, fast response, and sensitive control. The cluster system realizes the flat control of Jiuquan new energy base and effectively promotes the utilization of wind power in Jiuquan of Gansu province. Wind farms, photovoltaic power plants cluster control system structure shown in Fig. 5. 


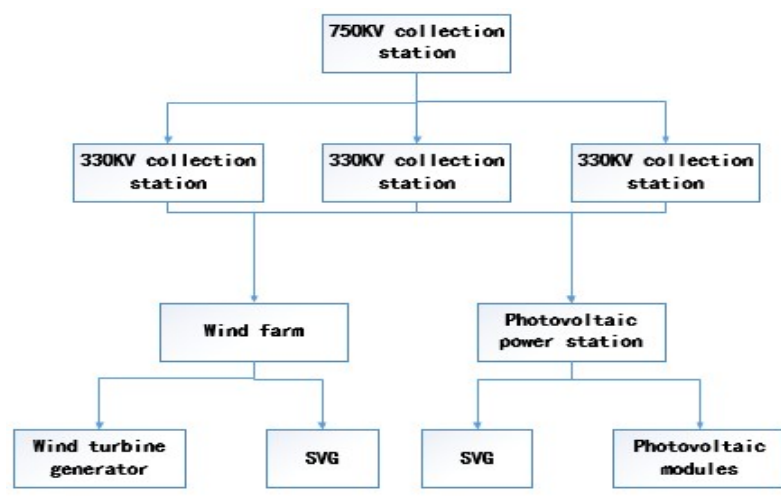

Fig. 4 Cluster reactive voltage control mode.

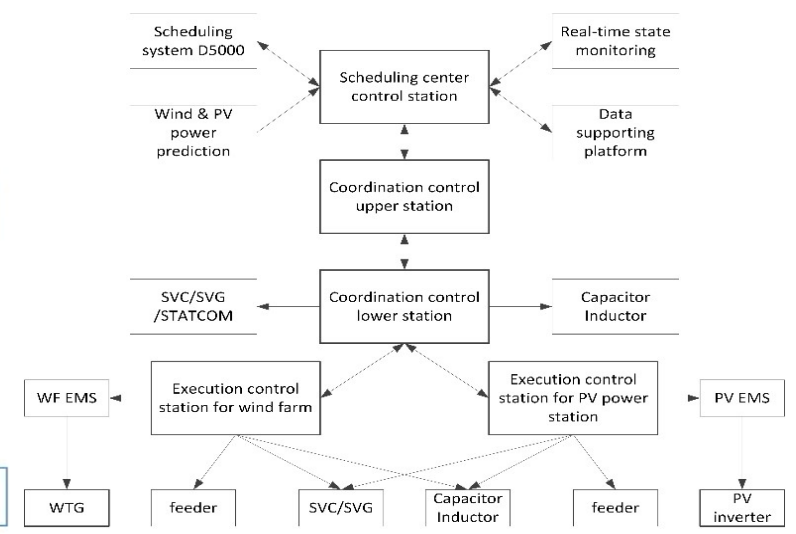

Fig. 5 landscape cluster control system structure diagram

\section{Cluster control system effect}

\section{Overall effect}

Large scale new energy cluster control system can integrate wind farms, photovoltaic power plant cluster which has a common access point and geographically adjacent, it can stabilize the randomness and volatility in output characteristics of wind power and photovoltaic power plants, which try to make them like conventional power plants in outside characteristics and has the ability to respond flexibly to large grid scheduling. The final effect of the cluster control system is shown in Fig. 6 .

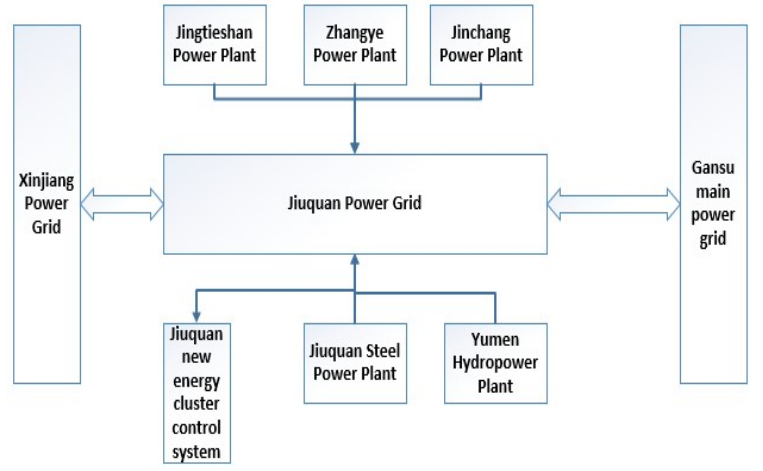

Fig. 6 Jiuquan large-scale cluster control system application effect diagram

\section{Effects verification}

In order to verify the control performance of the cluster system, select the system covered in Zhangye, Jinchang regional to analysis comparatively, the results shown in Table1.

Table 1 Comparison of the effect of the control system of the scenery cluster

\begin{tabular}{|l|c|c|}
\hline \multirow{2}{*}{ Test type name } & \multicolumn{2}{|c|}{ Effect } \\
\cline { 2 - 3 } & $\begin{array}{l}\text { Effect of cluster } \\
\text { system }\end{array}$ & $\begin{array}{l}\text { Direct effect of single } \\
\text { plant }\end{array}$ \\
\hline $\begin{array}{l}\text { Cluster unit1 power } \\
\text { utilization }\end{array}$ & $89.47 \%$ & $87.26 \%$ \\
\hline $\begin{array}{l}\text { Cluster unit2 power } \\
\text { utilization }\end{array}$ & $96.00 \%$ & $94.54 \%$ \\
\hline $\begin{array}{l}\text { The conventional unit } \\
\text { power cost(\$MWH) }\end{array}$ & 19.51 & 19.82 \\
\hline $\begin{array}{l}\text { The unit cost of } \\
\text { electricity (\$/MWH) }\end{array}$ & 14.71 & 15.20 \\
\hline $\begin{array}{l}\text { Safety dispatching time } \\
\text { scale }\end{array}$ & $93.52 \%$ & $83.06 \%$ \\
\hline $\begin{array}{l}\text { Zhangye,jinchang wind } \\
\text { power capacity(MW) }\end{array}$ & 120 & 40 \\
\hline
\end{tabular}

It can be known from the above table that the cluster system has many advantages over the control system of single wind power farm, and it can promote the capacity of grid connected from 400,000 kilowatts to 1.2 million kilowatts, reducing the abandoned wind power.

Therefore, both in the field of new energy technologies or in the existing schedule operating mode, the cluster control system is a new exploration and a advanced technology significantly. 


\section{Summary}

Under the background of China's large-scale, centralized development of new energy sources, in order to solve the technical problems in large-scale new energy base of China, Gansu Electric power company independently developed the large-scale scenery cluster control system, this paper mainly introduces the functions and features of the system.

Running results shown that the wind farm and photovoltaic power station cluster control system can effectively stabilize the output randomness and fluctuation of single wind farm and photovoltaic power, it also can effectively improve the utilization rate of new energy. The results of the cluster system play an exemplary and promoting role in the construction of large-scale scenery base in China, which can be popularized and applied in other large-scale new energy sources in China; It provides the technical reference for the high permeability access of the local area network in the east province in China.In the international arena, this research findings can provide a construction and operation Chinese-style templates for large-scale desert solar photovoltaic cluster in North Africa and large-scale offshore wind power development in Europe. This technology realizes the transformation of our country to follow the control technology of the use of renewable energy to the scale of the leader's role.

\section{Acknowledgements}

This work was financially supported by the State Grid Program(52272718000J) and State Grid of Gansu Electric Power Company Program(52272716000G)

\section{Reference}

[1] Liu Zhenya global energy Internet [M], China Electric Power Press.

[2] Zhou Qiang, Wang Ningbo, He Shien, Ma Yanhong, Wang Xiaoyong et al. Gansu opto development analysis and measures for power grid enterprises to study [J]. grid and clean energy.2014, 30 (4): 60-67

[3] Zhou Qiang, Wang Ningbo, Shi en he etc.. Promote the Jiuquan wind power with long distance transmission and consumptive policy [J]. Gansu science and technology.2012,29 (2),: 1-5

[4] HE Shi-en,DONG Xinzhou.Cause analysis on large-scale wind turbine tripping and its countermeasures[J].Power System Protection and Control,2011,40(1):131-137.

[5] HE Shi-en, ZHENG Wei, ZHI Yong, et al. Power quality issues of large-scale cluster wind power integration[J].Power System Protection and Control, 2013, 41(2):39-44.

[6] Dong Yongping, He Shien, Liu Jun, Zhou Qiang et al.. [J]. wind power consumption problem in the view of low carbon power. Power system protection and control, 2014,42 (5): 12-16

[7] LIU Xin-dong, FANG Ke, CHEN Huan-yuan, et al.Research on rational wind power casting theory for large-scale wind power integration improvement[J].Power System Protection and Control, 2012, 40(6):35-39.

[8] XU Qian-yao, KANG Chong-qing, JIANG Chang-ming,et al. Preliminary analysis on wind poweraccommodation system from multiple temporal and spatial scale perspective[J]. Power System Protection and Control, 2013, 41(1): 28-32. 